\title{
Time Window of Autoreceptor-Mediated Inhibition of Limbic and Striatal Dopamine Release
}

\author{
PAUL E.M. PHILLIPS, PAMELA J. HANCOCK, AND JONATHAN A. STAMFORD* \\ Neurotransmission Laboratory, Academic Department of Anaesthesia and Intensive Care, Barts and The London \\ School of Medicine and Dentistry, Alexandra Wing, Royal London Hospital, Whitechapel, London E1 1BB, UK
}

\begin{abstract}
KEY WORDS dopamine; autoreceptor; voltammetry; brain slice
ABSTRACT Forebrain dopamine release is under the local control of D2 family (D2 and D3) autoreceptors. In this study, autoreceptor-mediated modulation of forebrain dopamine release was investigated using amperometry in brain slices following local electrical stimulation. $350 \mu \mathrm{m}$-thick slices of nucleus accumbens or dorsolateral neostriatum were prepared from male Wistar rats (150-200 g) and superfused with artificial cerebrospinal fluid at $32^{\circ} \mathrm{C}$. Dopamine release was evoked by electrical pulses $(0.1 \mathrm{~ms}, 10 \mathrm{~mA})$ across bipolar tungsten stimulating electrodes and measured at carbon fibre microelectrodes using fixed potential amperometry ( $+300 \mathrm{mV}$ vs. $\mathrm{Ag} / \mathrm{AgCl})$. Peak dopamine release on stimulation (single pulse) was $0.75 \mu \mathrm{M}$ (neostriatum) and $1.37 \mu \mathrm{M}$ (nucleus accumbens). Metoclopramide $(1 \mu \mathrm{M})$ had no significant effect on DA efflux from a single pulse in either region. Using paired pulse stimuli, dopamine release on the second pulse varied according to the interval between the two pulses. At very long intervals ( $>20 \mathrm{sec}$ ), dopamine release was similar to that for the first pulse. At shorter intervals, dopamine efflux was attenuated. Metoclopramide had no effect on second pulse dopamine release when the pulse was applied at short $(<0.1 \mathrm{sec})$ or long $(>5.0 \mathrm{sec})$ intervals after the first. At intermediate intervals, metoclopramide significantly increased second pulse dopamine release. The peak dopamine autoreceptor effect occurred at $\sim 550 \mathrm{~ms}$ in neostriatum and $\sim 700 \mathrm{~ms}$ in nucleus accumbens. The onset time is due both to diffusion of dopamine from the release sites to the autoreceptors and receptoreffector mechanisms. These findings may have implications for the local control of forebrain dopamine function in physiological and pathological states. Synapse 44: 15-22, 2002. ๑ 2002 Wiley-Liss, Inc.
\end{abstract}

\section{INTRODUCTION}

Most midbrain dopamine neurones are located in the substantia nigra or ventral tegmental area and project broadly to the neostriatum and limbic forebrain (nucleus accumbens, olfactory tubercle, amygdala, prefrontal cortex), respectively. These neurones fire at approximately 5 $\mathrm{Hz}$ in conscious animals but may express this firing in either regularly paced action potentials or in short bursts (Grace and Bunney, 1983, 1984; Freeman et al., 1985). It has been shown by Gonon and colleagues that both the frequency and pattern of afferent activity determines the magnitude of dopamine release in the terminal fields (see Gonon, 1997). Moreover, drugs that modify dopamine cell firing rate may also modify the pattern of firing (White and Wang, 1983a,b) in a manner that makes the consequences for dopamine release hard to predict.

Dopamine release within the terminal arborisations is evoked both by the afferent traffic from the midbrain and glutamate released from cortical projections (Grace, 1991). It is modulated by negative-feedback through autoreceptors located on the dopaminergic terminals which can alter dopamine synthesis (transmitter content per vesicle) and secretion (vesicles released per impulse). Activation of these autoreceptors decreases dopamine release while dopamine antagonists increase release in circumstances where there is significant agonist tone at the receptor.

In the present study we investigated the operational characteristics of the striatal and limbic dopamine ter-

Current address for Paul E.M. Phillips: Department of Chemistry and Neuroscience Center, University of North Carolina, Chapel Hill, NC 27599-3290, USA.

*Correspondence to: Dr. J.A. Stamford, Neurotransmission Lab, Anaesthetics Unit, Royal London Hospital, Whitechapel, London E1 1BB, UK.

E-mail: j.a.stamford@qmul.ac.uk

Received 5 June 2001; Accepted 4 December 2001 
minal autoreceptors. Specifically, we sought to examine the temporal profile of the autoreceptor in response to activation by endogenous dopamine (the 'time window') and to relate this to its physiological profile of activation.

\section{MATERIALS AND METHODS}

Dopamine release was measured by amperometry at carbon fibre microelectrodes in slices of rat neostriatum and nucleus accumbens following local pairedpulse electrical stimulation, in the presence or absence of the dopamine receptor antagonist metoclopramide.

\section{Brain slices}

Slices of neostriatum or nucleus accumbens were prepared according to the basic method of Bull et al. (1990). Briefly, male Wistar rats (150-200 g) were sacrificed by cervical dislocation and their brains removed and chilled in ice-cold artificial cerebrospinal fluid (aCSF). A block, approximately AP: +11.0 to $+6.0 \mathrm{~mm}$ vs. the interaural line (Paxinos and Watson, 1986) was cut and sequential slices $(350 \mu \mathrm{m})$ were taken using a vibratome (Campden $352 \mathrm{M}$ ) to acquire the desired rostrocaudal section. The slices were then placed in a holding chamber of aCSF at room temperature for at least $1 \mathrm{~h}$ to recover from sectioning and then transferred to the recording chamber and superfused with aCSF at $32^{\circ} \mathrm{C}$ throughout the experiment. An equilibration time of $30 \mathrm{~min}$ before the first stimulation was used.

\section{Electrodes}

Cylindrical carbon fibre microelectrodes with a diameter of $7 \mu \mathrm{m}$ and a length of 30-50 $\mu \mathrm{m}$ (Armstrong James and Millar, 1979) were used for the detection of dopamine. Electrodes to be used for amperometry were subjected to a fixed potential (+300 mV vs. Ag/AgCl) for at least $1 \mathrm{~h}$ when new, and for $30 \mathrm{~min}$ before each experiment. Electrodes were implanted into either the core of the nucleus accumbens or the dorsolateral quadrant of the neostriatum.

The reference electrode was an $\mathrm{Ag} / \mathrm{AgCl}$ cylinder (World Precision Instruments, New Haven, CT), encapsulated in an insulating tube. This was positioned in a purpose-drilled well in the recording chamber so that the $\mathrm{Ag} / \mathrm{AgCl}$ surface was submerged in aCSF.

The stimulating electrode was a parallel bipolar microelectrode with a tip separation of approximately 500 $\mu \mathrm{m}$, made from two single epoxy-insulated tungsten microelectrodes (diameter $125 \mu \mathrm{m}$; A-M Systems, Everett, WA). These were joined together with cyanoacrylate glue and the tips gently sanded with fine emery paper to lower their impedance.

\section{Electrical stimulation}

Throughout this work, paired-pulse stimuli were used, consisting of two pulses $(0.1 \mathrm{~ms}, 10 \mathrm{~mA})$ sepa- rated by $50 \mathrm{~ms}, 100 \mathrm{~ms}, 200 \mathrm{~ms}, 500 \mathrm{~ms}, 1 \mathrm{sec}, 2 \mathrm{sec}, 5$ sec, $10 \mathrm{sec}, 20 \mathrm{sec}$, or $50 \mathrm{sec}$. Pulse pairs were applied at intervals of $5 \mathrm{~min}$ throughout. The amplitude of dopamine release for the second pulse was expressed as a percentage of that on the first (S2/S1 ratio). Some experiments were performed in the presence of the D2like antagonist metoclopramide $(1 \mu \mathrm{M})$ to evaluate the role of dopamine autoreceptors.

\section{Amperometric detection of dopamine}

Dopamine release was measured by constant potential amperometry using a two-electrode 'MicroC' potentiostat (World Precision Instruments, Hertfordshire, UK). The fixed output potential to the working electrode was set to $+300 \mathrm{mV}$ vs. $\mathrm{Ag} / \mathrm{AgCl}$ for detection of dopamine.

The current output was also recorded on a digital storage oscilloscope (250 Hz sampling; NIC-310DD, Nicolet). A pretrigger was set to start recording 200$500 \mathrm{~ms}$ before the first pulse and once the oscilloscope completed its scan the data was automatically stored to a floppy disk. These data were then analysed off-line using Fast Analysis and Monitoring of Signals (FAMOS) software (IMC Mess-Systeme GmbH, Berlin, Germany).

Where the pulse separation was very short, the dopamine signal for each of the pulses would overlap and summate. In this situation, the output from a single pulse stimulation was digitally subtracted from it, using FAMOS, so that dopamine could be measured accurately for the second pulse (Fig. 1).

Postexperimental calibration of electrodes was carried out with a flow injection apparatus. The working electrode was placed in a flow stream superfused with aCSF $(2 \mathrm{ml} / \mathrm{min})$ via a syringe pump.

\section{Drugs and chemicals}

Stock solutions of metoclopramide hydrochloride (SmithKlineBeecham Pharmaceuticals, Surrey, UK) were prepared in distilled water and kept frozen until the day of use. Dopamine hydrochloride (Sigma Chemical Co., St. Louis, MO) was diluted in $0.1 \mathrm{M} \mathrm{HCl}$ and refrigerated. Final solutions of these compounds were made by 1,000 -fold dilution in aCSF.

Artificial CSF was composed of $\mathrm{NaCl}$ (124 mM), KCl (2.00 mM), $\mathrm{KH}_{2} \mathrm{PO}_{4}(1.25 \mathrm{mM}), \mathrm{MgSO}_{4} \cdot 7 \mathrm{H}_{2} \mathrm{O}(2.00$ $\mathrm{mM}), \mathrm{NaHCO}_{3}(25.0 \mathrm{mM}), \mathrm{CaCl}_{2}(2.00 \mathrm{mM})$, and (+)glucose $(11.0 \mathrm{mM})$. These salts were purchased from $\mathrm{BDH}$ (Dorset, UK). The solution was gassed at $32^{\circ} \mathrm{C}$ with $95 \% \mathrm{O}_{2} / 5 \% \mathrm{CO}_{2}$ before use.

\section{Data analysis and statistics}

Signals obtained in the presence or absence of metoclopramide were compared by Student's $t$-test using Prism software (GraphPad Software, San Diego, CA). 

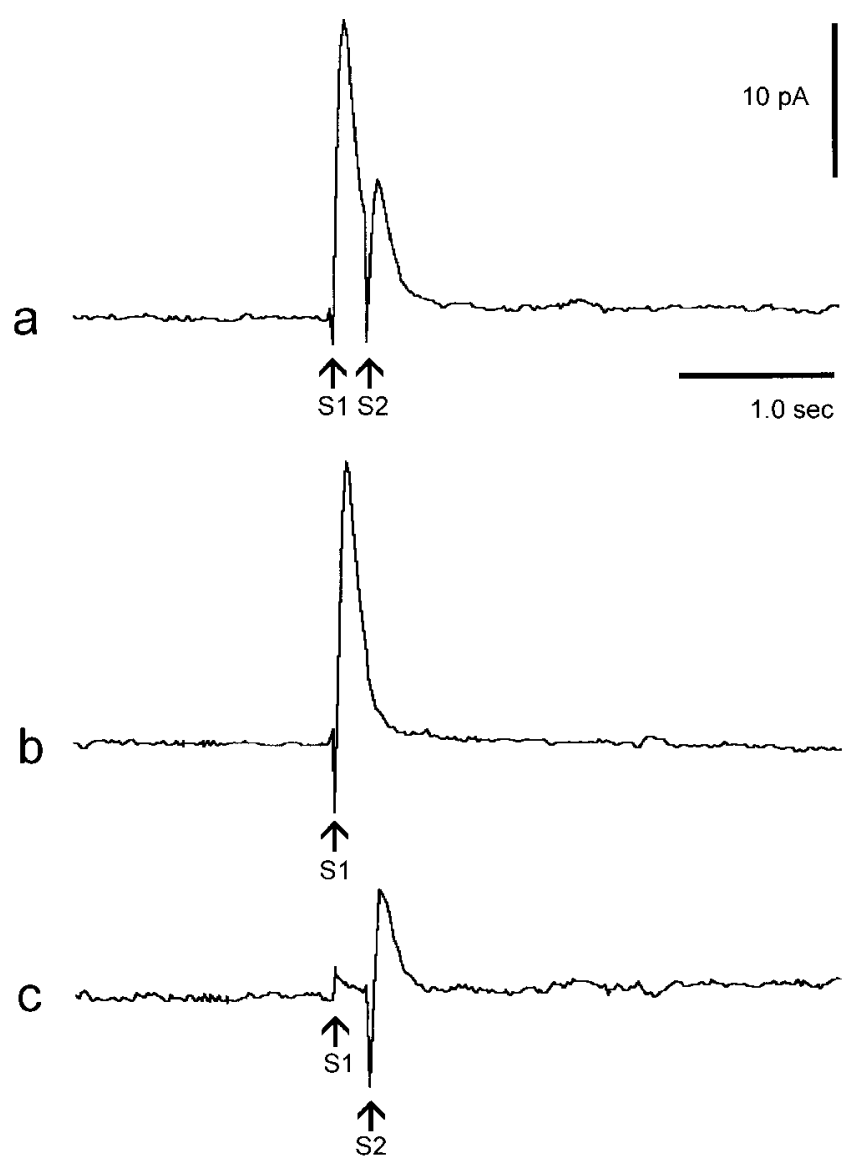

Fig. 1. Resolution of dopamine release for the second pulse by digital subtraction. A representative time-synchronised record of dopamine release for a single pulse stimulation (b) was subtracted from that obtained with paired pulse stimulation (a) to unmask the dopamine release signal for the second pulse alone (c).

TABLE I. Dopamine release in striatum and nucleus accumbens

\begin{tabular}{lcc}
\hline & Nucleus accumbens & Neostriatum \\
\hline Controls & $1.37 \pm 0.11 \mu \mathrm{M}$ & $0.75 \pm 0.19 \mu \mathrm{M}^{*}$ \\
Metoclopramide $(1 \mu \mathrm{M})$ & $1.18 \pm 0.31 \mu \mathrm{M}$ & $1.01 \pm 0.22 \mu \mathrm{M}$ \\
\hline
\end{tabular}

DA release for the first of two electrical pulses (or single pulse) in nucleus accumbens $(n=4)$ and dorsolateral neostriatum $(n=5)$ in control or metoclopramide slices (mean \pm SEM).

${ }^{*} P<0.05$ vs. nucleus accumbens controls.

\section{RESULTS}

Electrical stimulation consistently evoked dopamine release. Table I shows the peak extracellular concentrations attained in both neostriatum and nucleus accumbens following single pulse stimulation. Figure 2 shows raw amperometric data of dopamine release for a single pulse electrical stimulation $(0.1 \mathrm{~ms}, 10 \mathrm{~mA})$ and paired pulses separated by $500 \mathrm{~ms}$ in dorsolateral neostriatum. The recording of faradaic current for a single pulse stimulus (Fig. 2a) showed a short, initial, negative deflection (a current artifact of the stimulus) followed by a slower rise to reach a peak at typically 100-150 ms. This then decayed at a slower rate, returning to baseline after approximately $500-1,000 \mathrm{~ms}$. a

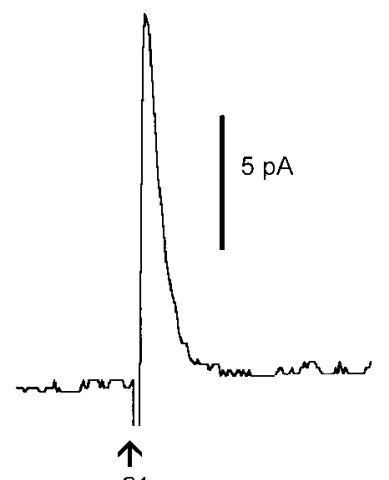

$\|_{10 \mathrm{pA}}^{\mathrm{S} 1}$

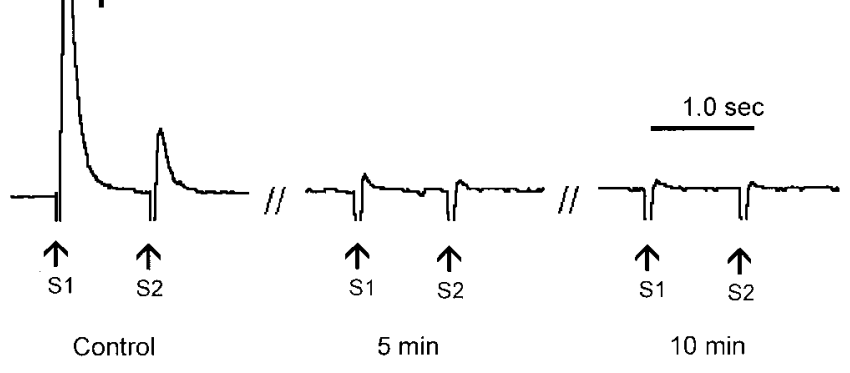

Time after calcium removal

Fig. 2. Raw traces of amperometric recordings of dopamine following electrical stimulations in the dorsolateral neostriatum. Applications of electrical pulses are represented by the arrows. a: Dopamine release following a single pulse. b: Dopamine release following two pulses separated by $500 \mathrm{~ms}$. c: The effect of calcium removal on stimulated dopamine release evoked by two electrical pulses (represented by the triangles) separated by 1 sec. The scale bars represent the faradaic current and time for each trace. This procedure was carried out at the end of each experiment to confirm calcium dependence.

For paired stimulus pulses (Fig. 2b), the second pulse also caused a negative deflection followed by a further rise to peak (after 100-150 ms), albeit much smaller (S2/S1: $\sim 25 \%$ ) than the first. The return to baseline occurred at a similar rate to that for the first pulse.

Following each experiment, the aCSF was replaced with calcium-free aCSF (equimolar substitution of calcium for magnesium) to confirm dopamine was being released in a calcium-dependent manner. In all cases, dopamine release was abolished within 15 min of calcium removal (Fig. 2c) inferring that dopamine release was exocytotic. In a proportion of experiments, the potential of the working electrode was set to $0.0 \mathrm{~V}$ vs. $\mathrm{Ag} / \mathrm{AgCl}$. Under these conditions, stimulation evoked no detectable current increment besides the stimulus artifact (data not shown), confirming that the measured signal was faradaic (oxidation) current of a rapidly released, readily oxidisable substance, i.e., dopamine (Dugast et al., 1994).

In order to study the timecourse of autoreceptor inhibition of dopamine release, paired-pulse stimulations 


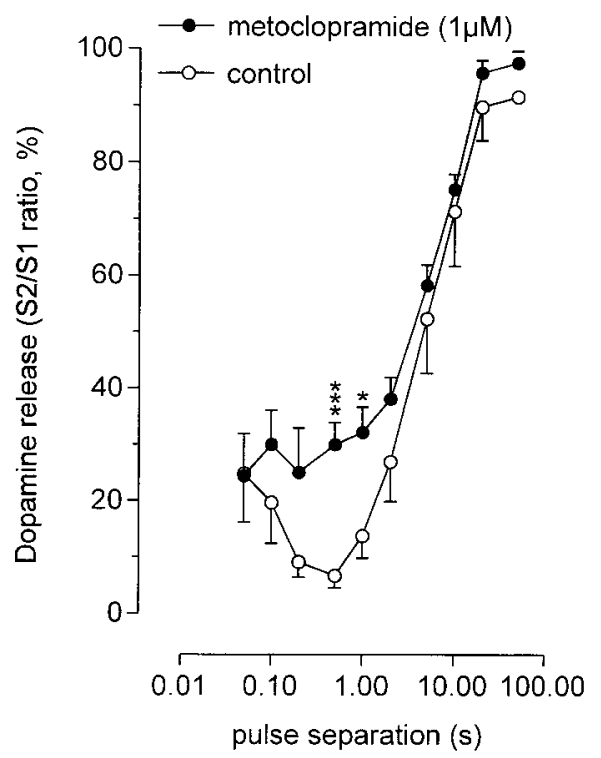

b

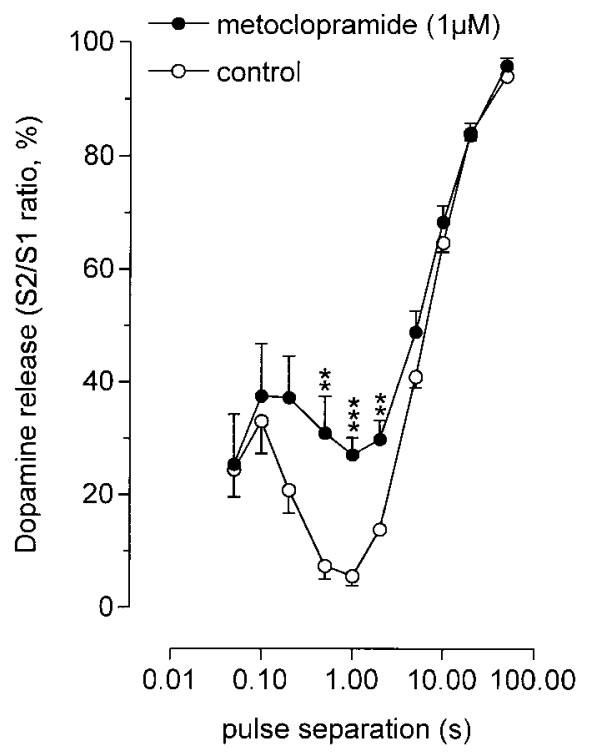

Fig. 3. Autoreceptor-mediated inhibition of stimulated dopamine release. Amplitude of dopamine release $(\mathrm{S} 2 / \mathrm{S} 1$ ratio, mean $\pm \mathrm{SEM}$; $\mathrm{n}=5$ ) for the second of two electrical pulses vs. pulse separation for (a) dorsolateral neostriatum and (b) core of the nucleus accumbens, carried out in the presence (filled circles) or absence (open circles) of $1 \mu \mathrm{M}$ metoclopramide. $* P<0.05, * * P<0.01, * * * P<$ 0.001 vs. control (unpaired $t$-test).

were used with a second electrical pulse (S2) applied at different times ( $50 \mathrm{~ms}$ to $50 \mathrm{sec}$ ) after the first (S1). The $\mathrm{S} 2 / \mathrm{S} 1$ ratio was assessed in the absence and presence of the D2-like antagonist, metoclopramide $(1 \mu \mathrm{M}$; applied throughout the experiment), to evaluate the autoreceptor effect.

Figure 3 shows dopamine release on the second electrical pulse (S2/S1 ratio as a percentage) for the different pulse separations. In control experiments, dopamine release on the second pulse was about $25 \%$ of that on the first for the shortest pulse separation $(50 \mathrm{~ms})$ in both nuclei. For increasing pulse separation, there was initially a decrease in the amplitude of dopamine release on S2 at intervals of 50-500 ms (for dorsolateral neostriatum) and $100 \mathrm{~ms}$ to $1 \mathrm{sec}$ (nucleus accumbens). $\mathrm{S} 2 / \mathrm{S} 1$ ratios then increased for increasing interpulse intervals until they approached $100 \%$ of $\mathrm{S} 1$ at $20-50$ sec intervals.

The "dip" in S2/S1 ratio at interpulse intervals above $50-100 \mathrm{~ms}$ was significantly reduced in metoclopramide-treated slices. In both nucleus accumbens and neostriatum, metoclopramide had no significant effect on dopamine release for S2 when it occurred either 200 $\mathrm{ms}$ or less, or 5 sec or more after S1. Metoclopramide did not increase dopamine release on single pulse stimuli (Table I).

Subtraction of the dopamine release (S2/S1) in the presence of metoclopramide from controls unmasked that component of the curve that was directly attributable to autoreceptor activation (Fig. 4). Gaussian curves fitted to these data described the window of effect $\left(\mathrm{r}^{2}=0.96\right.$ for neostriatum and 0.99 for nucleus accumbens).

The peak of each of the fitted curves represents maximum inhibition of dopamine release by D2-like recep-

a

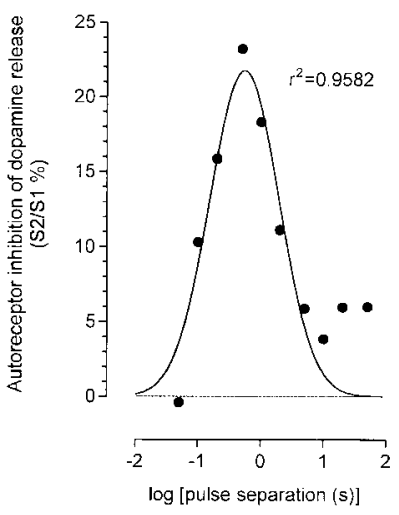

b

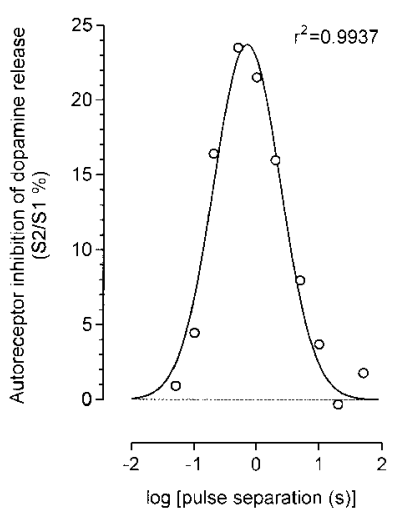

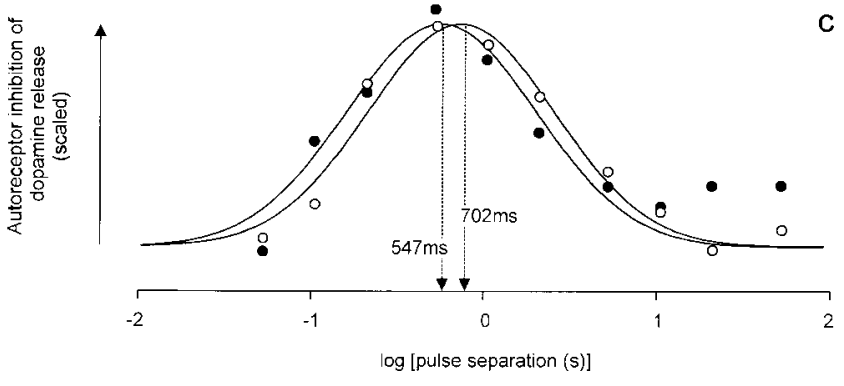

Fig. 4. Time dependency of autoinhibition of dopamine release. Mean differences in amplitude of dopamine release for the second of two electrical pulses between metoclopramide $(1 \mu \mathrm{M})$ treated and control slices plotted against pulse separation $(n=5)$ in $(\mathbf{a})$ dorsolateral neostriatum or (b) core of the nucleus accumbens (error bars omitted for clarity). Gaussian curves fitted to the data describe the temporal profile of autoreceptor action. The lower panel (c) shows the data of parts $\mathbf{a}$ and $\mathbf{b}$, normalised to the same height and on an expanded $\mathrm{x}$ axis, for clarity. 
tors and falls between $500 \mathrm{~ms}$ and $1 \mathrm{sec}$ for both nuclei (547 ms for neostriatum and $702 \mathrm{~ms}$ for nucleus accumbens).

\section{DISCUSSION}

It has previously been shown that local electrical stimulation in striatal slices releases dopamine that may successfully be detected by electrochemical methods at carbon fibre microelectrodes. With fast cyclic voltammetry in brain slices of the neostriatum or nucleus accumbens, the background-corrected cyclic voltammogram following electrical stimulation is always indicative of dopamine (Stamford et al., 1995). The only other bioactive compound that gives a cyclic voltammogram like dopamine is noradrenaline. Therefore, significant interference from serotonin and all other compounds other than noradrenaline can be excluded. In addition, interference from noradrenaline should be minimal because of its relatively low tissue levels in the regions of interest. Furthermore, the signal is reduced by tetrodotoxin, reserpine, and calcium removal and is increased by the dopamine uptake inhibitor GBR 12909 (Bull et al., 1990). Although no analytical technique offers $100 \%$ specificity, these extensive characterisation data collectively suggest that dopamine is the only readily oxidisable species that changes in concentration following electrical stimulation of these slices. It follows, therefore, that dopamine is the predominant species detected with amperometry $(+300$ $\mathrm{mV}$ vs. $\mathrm{Ag} / \mathrm{AgCl}$ ) under these same controlled conditions.

When dopamine is released following action potential invasion of the terminal fields, it can activate presynaptic autoreceptors which inhibit subsequent release of dopamine (see Langer, 1997). In the neostriatum and nucleus accumbens, dopamine autoinhibition is mediated via dopamine D2-like receptors (Dugast et al., 1997). Although other in vitro studies have demonstrated that activation of release-regulating autoreceptors by short trains of pulses occurs over a time frame of approximately $1 \mathrm{sec}$ (Limberger et al., 1991; Kennedy et al., 1992), the explicit timecourse of action of these autoreceptors on subsequent dopamine release has not been previously determined. Yet the window of such autoinhibition (onset, magnitude, and duration) clearly has important implications for the local control of extracellular dopamine in the forebrain. In the present study, we used amperometry in an effort to describe the precise kinetics of autoreceptor activation in two clinically relevant dopamine terminal fields. Amperometry has extremely high time resolution (Kawagoe and Wightman, 1994; Dugast et al., 1997) and is ideal for measurement of extracellular transmitter dynamics (Budygin et al., 2001).

It is notable from Figure 3 that dopamine release on $\mathrm{S} 2$ is consistently smaller than on $\mathrm{S} 1$ at all but the longest interpulse intervals. The $\mathrm{S} 2 / \mathrm{S} 1$ ratios are sim- ilar in neostriatum and nucleus accumbens. Since much of this pattern persists, even in the presence of metoclopramide, there is clearly restriction of dopamine release independent of the autoreceptor-mediated inhibition. Paired-pulse inhibition has been observed in other in vitro studies (Higgins and Stone, 1993) and may reflect the time needed for mobilisation and docking of further vesicles at the presynaptic membrane (Parsons et al., 1995). It has also recently been demonstrated that different voltage-gated calcium channels are recruited to dopamine release on the first and subsequent pulses of a stimulus train (Phillips and Stamford, 2000), perhaps also contributing to this effect. Possibly, inhibition of dopamine release by other neurotransmitters released by the stimulation, acting at heteroreceptors (an effect not present during stimulation of the afferent pathway), may contribute to the D2-independent attenuation (Phillips and Stamford, 1996; Wu et al., 2000).

A key part of the $\mathrm{S} 2$ inhibition is directly attributable to autoreceptor activation, since it can be reduced by metoclopramide $(1 \mu \mathrm{M})$. The autoreceptor in the dopaminergic forebrain is of the D2 family and it is reported that both terminal D2 and D3 autoreceptors may regulate striatal and limbic dopamine release (Patel and Kruk, 1996). Metoclopramide has similar affinity for D2 and D3 dopamine receptors (Sokoloff et al., 1992) and thus it is not possible to ascribe the autoinhibition observed here to a single subtype. Although metoclopramide also blocks $5-\mathrm{HT}_{3}$ receptors, we are confident that the effects observed here are mediated through D2 family dopamine receptors for two reasons. First, $5-\mathrm{HT}_{3}$ receptor stimulation facilitates striatal dopamine release (Blandina et al., 1989) and thus a $5-\mathrm{HT}_{3}$ antagonist should reduce rather than increase dopamine release. Second, we find identical results with haloperidol (Phillips and Stamford, 1998) and domperidone (data not shown), both selective D2 antagonists that do not affect 5-HT function.

Of course, D2-like receptors are present not only on dopaminergic terminals but also on GABA spiny neurons, cholinergic interneurons, and possibly glutamatergic terminals. By blocking D2-like receptors on these components, metoclopramide could theoretically influence dopamine release independent of dopamine autoreceptors. However, this possibility can be excluded due to the nature of the experiments. Metoclopramide has no effect on dopamine release from single pulses, indicating that there is no basal tone (between stimuli) at $\mathrm{D} 2$ receptors in the brain slice. Likewise, NMDA and $\mathrm{GABA}_{\mathrm{A}}$ antagonists (Phillips and Stamford, 1996) and nicotinic antagonists (data not shown) do not alter dopamine release for a single pulse, suggesting that glutamate, GABA, and acetylcholine provide no basal influence on dopamine release under the present conditions also. Under these conditions dopamine could modulate dopamine release on the second 
stimulus only via autoreceptors and would require subsequent stimuli for effects via local circuitry (modulating glutamate, GABA, or acetylcholine, for instance) to be manifested.

To illustrate this, consider for instance that D2 receptors were present on the cell bodies of an interneurone that formed excitatory synapses on dopaminergic terminals. Through this circuitry we could reconcile that D2 activation would cause an inhibition of the interneurone, and therefore remove the excitatory input at the dopaminergic terminal, thus reducing dopamine release. Since there is no functional transmitter tone in the brain slice (dopamine release for a single electrical pulse is not inhibited by glutamate, GABA, or acetylcholine antagonists) for the interneurone to influence dopamine release, its transmitter must be released by the stimulation (which is very feasible). However, it is unlikely that this receptor-effect could occur during the course of the stimulation $(100 \mu \mathrm{s})$ per se (demonstrated by the fact that antagonists do not alter single-pulse dopamine release) and so the effect must first be manifested on the next stimulation pulse. Dopamine released by the first pulse would activate both D2 autoreceptors and D2 receptors on the interneurones. This would then inhibit dopamine release (via autoreceptors) and evoked release from the interneurone on the next stimulation pulse. However, for the (now altered) release of transmitter from the interneurone on pulse 2 to influence dopamine release, a third pulse would be required. In all scenarios where there is functionally insignificant basal neurotransmitter tone, and responses are evoked by short, discrete stimuli, the number of stimulation pulses required to observe a feedback effect in a circuit is equal to one more than the number of synapses in the pathway, i.e., the effect is observed on the second pulse for an monosynaptic autoreceptor circuit, on the third pulse for a bisynaptic pathway, and on subsequent pulses for a polysynaptic pathway.

By subtracting data obtained in the presence of metoclopramide from drug-free controls, the exact time course of autoinhibition may be unmasked (Fig. 4). The graphs show that maximal autoreceptor effect occurs at $\sim 550 \mathrm{~ms}$ in neostriatum and $\sim 700 \mathrm{~ms}$ in nucleus accumbens. Significantly, the graphs also clearly demonstrate a minimum time period necessary for autoreceptor action and a maximum time after which the autoreceptor ceases to be effective, these limits defining the 'window' of autoreceptor action. The timecourse of autoreceptor activation demonstrated here supports the general findings of previous studies carried out in vitro where autoreceptor antagonism did not significantly increase transmitter release for electrical trains of less than $500 \mathrm{~ms}$ (Cejna et al., 1990). Furthermore, these times are similar to those observed for postsynaptic activation following stimulation of dopamine neurones (Williams and Millar, 1990; Gonon, 1997).
The temporal profile of this window inevitably reflects both the diffusion of dopamine from the release site to the receptors and the intracellular transduction of autoreceptor activation to the resultant response. If the period required to attain maximum autoreceptor action was wholly due to the time needed for released dopamine to diffuse to its receptors $(t)$, the mean diffusion distance $(l)$ could be calculated using the diffusion coefficient $(D)$ from the equation $l=\sqrt{D t}$. To account for the tortuosity $(\lambda)$ of the brain, the diffusion coefficient can be corrected to the apparent diffusion coefficient $\left(D^{*}\right)$ by $D^{*}=D / \lambda^{2}$. The derived value of the free diffusion coefficient for dopamine at $32^{\circ} \mathrm{C}$ is $6.9 \times 10^{-6}$ $\mathrm{cm}^{2} / \mathrm{sec}$ (Gerhardt and Adams, 1982) and tortuosity in the rat neostriatum is 1.54 (Rice and Nicholson, 1991). Applied to the present data, mean diffusion distances of $12.6 \mu \mathrm{m}$ for the neostriatum and $15.0 \mu \mathrm{m}$ for the nucleus accumbens are obtained. In essence, these would correspond to the average distances of the autoreceptors from the release sites. Interestingly, these relative values are consistent with the data of Missale et al. (1985), who showed that there were fewer dopamine uptake sites in the nucleus accumbens, meaning therefore that dopamine could diffuse further than in the neostriatum (Stamford et al., 1988).

These distances should be thought of as upper limits, since they assume that autoreceptor action occurs instantaneously when dopamine activates the receptors. Consequently, to further study feasible diffusion distances following stimulation, dopamine terminals can be considered a network of point sources of dopamine. The concentration distribution from a point source with respect to distance at any time after application is described by a Gaussian decay with a standard deviation $(\sigma)$ that is a function of time: $\sigma=2 \mathrm{Dt}$. For a homogenous distribution of multiple point sources, there will be uniform concentration of the applied substance once the standard deviation reaches the separation distance of the point sources. The separation of dopamine varicosities is $\sim 4 \mu \mathrm{m}$ (Doucet et al., 1986), and hence by rearranging the equation the time following stimulation to reach uniform dopamine extracellular dopamine concentration (assuming there is release from all varicosities) can be calculated as $\sim 28 \mathrm{~ms}$. However, in this study the dopamine concentration at the electrode continued to increase for $100-150 \mathrm{~ms}$ after the stimulation, suggesting that the separation of release sites is actually greater than $4 \mu \mathrm{m}$. If the standard deviation of the dopamine concentration distribution is calculated at these times, it would suggest that the distance between active dopamine release sites is 7.6-9.3 $\mu \mathrm{m}$, implying that either 1) dopamine is released from only a fraction of the varicosities for each stimulation, or 2) the release sites are clustered. Nevertheless, since the extracellular space most likely rapidly reaches a uniform dopamine concentration (in this $100-150 \mathrm{~ms}$ ), it suggests that much of the time to reach 
peak autoreceptor action occurs after dopamine reaches the receptors and hence it can be attributed to receptor transduction.

Indeed, recent work using photolysis of caged dopamine agrees that much of the time necessary for functional autoreceptor activation is attributable to the intracellular second messenger cascade: The process of photolytic dopamine release is rapid $(\sim 100-200 \mathrm{~ms}$; Lee et al., 1996), yet inhibition of electrically evoked dopamine release by uncaged dopamine still takes approximately $1 \mathrm{sec}$ to reach maximum (Tong Lee, pers. commun.). Considering the different methodological approaches, this value is in excellent agreement with those of the present study.

It should be noted that in this study we used a single stimulus intensity to evoke dopamine release, and so did not test the dependence of the timecourse on this. However, a recent report (Benoit-Marand et al., 2001a) stated that "paired-pulse inhibition of dopamine release and its delayed recovery was not different in sagittally-cut striatal slices if the distance between the stimulating electrode and the amperometric electrode was increased from $\sim 100 \mu \mathrm{m}$ to $1000 \mu \mathrm{m}$, although the total dopamine overflow was reduced," suggesting that the data are not compromised by variability in dopamine release.

Midbrain dopamine neurones typically fire either regularly (tonic) or in short bursts (phasic) and may change between these two patterns (Grace and Bunney, 1983, 1984). It has been extensively shown by Gonon and colleagues that this has direct bearing on the levels of extracellular dopamine in the terminal fields (Chergui et al., 1994). For instance, repetitive burst stimulation of the median forebrain bundle (intraburst pulse interval $=70 \mathrm{~ms}$ ) induces significantly greater dopamine release than the same number of stimulus pulses spaced at regular intervals $(200 \mathrm{~ms})$, even though the average frequency is identical in each case (Gonon, 1988).

From Figures 3 and 4 it can be seen that autoreceptor activation is barely detectable at $70 \mathrm{~ms}$ but is pronounced after $200 \mathrm{~ms}$. Thus, the frequency of afferent action potential traffic directly affects autoreceptor activation and, by inference, postsynaptic receptor stimulation. Autoinhibition in the terminals will be induced much more effectively during tonic firing at $\sim 5 \mathrm{~Hz}$ (Grace and Bunney, 1983) than within a burst (Grace and Bunney, 1984). Furthermore, in salient behavioral situations midbrain dopamine neurones are reported to fire synchronously in bursts (Schultz, 1986). This doubtlessly causes dopamine release from many terminals simultaneously and results in very high, but transient, concentrations of extracellular dopamine (Rebec et al., 1997; Robinson et al., 2001). The window of autoreceptor action demonstrated here would permit the rapid rise in dopamine for the burst, while curbing dopamine levels during periods of tonic firing. This level of control would act to enhance the contrast in dopamine concentration for such behavior cues. However, autoreceptors are not only activated by dopamine evoked by neuronal firing, but also by dopamine tone that is putatively maintained by glutamate from corticostriatal and corticoaccumbal afferents. Regulation of these pathways (altering the tonic dopamine) also controls the level of inhibition of dopamine by autoreceptors (Grace, 1991), adding an additional level of complexity to control of phasic dopamine release.

It is worth reminding the reader nevertheless that the current data were acquired in vitro. The extent to which the same processes hold sway in vivo is currently unknown. Certainly the slice preparation has limited spontaneous activity and does not always mirror the in vivo state (Benoit-Marand et al., 2001a), although autoreceptor inhibition of striatal dopamine release has been demonstrated in vivo (Dugast et al., 1997). It will be interesting to see the extent to which these and other factors participate in vivo. A recent in vivo report using D2 receptor mice finds a similar overall profile of autoinhibition to the present study with a clear onset and offset but slightly shorter peak time (Benoit-Marand et al., 2001b). Considering the methodological differences (in vivo vs. in vitro, D2 knockout mice vs. pharmacological D2 receptor blockade in rats), the findings are encouragingly consonant.

In conclusion, dopamine release for a second electrical pulse is restricted by two independent phenomena in vitro. There is a general recovery in dopamine release with increasing interval after the first pulse, and superimposed upon this is a "dip," due to D2-like autoreceptor activation which can be diminished by metoclopramide. Dopamine autoinhibition takes up to 500 $\mathrm{ms}$ to become detectable and persists for less than 5 sec. The onset time may be due to a delay engendered by diffusion of dopamine from the release sites to the autoreceptors and slow transduction of the autoreceptor activation event. These findings may have implications for the local physiological and pharmacological control of forebrain dopamine function.

\section{REFERENCES}

Armstrong James M, Millar J. 1979. Carbon fibre microelectrodes. J Neurosci Meth 1:279-287.

Benoit-Marand M, Schmitz Y, Gonon F, Zhang H, Sulzer D. 2001a. Monitoring dopamine release under in vivo and in vitro conditions. Proc 9th Int Conf In Vivo Methods, Dublin, 227-228.

Benoit-Marand M, Borrelli E, Gonon F. 2001b. Inhibition of dopamine release via presynaptic D2 receptors: time course and functional characteristics in vivo. J Neurosci 21:9134-9141.

Blandina P, Goldfarb J, Craddock-Royal B, Green JP. 1989. Release of endogenous dopamine by stimulation of 5-hydroxytryptamine3 receptors in rat striatum. J Pharmacol Exp Ther 251:803-809.

Budygin EA, Phillips PEM, Robinson DL, Kennedy AP, Gainetdinov RR, Wightman RM. 2001. Effect of acute ethanol on striatal dopamine neurotransmission in ambulatory rats. J Pharmacol Exp Ther 297:27-34.

Bull DR, Palij P, Sheehan MJ, Millar J, Stamford JA, Kruk ZL, Humphrey PPA. 1990. Application of fast cyclic voltammetry to measurement of electrically evoked dopamine overflow from brain slices in vitro. J Neurosci Meth 32:37-44. 
Cejna M, Agneter E, Drobny H, Valenta B, Singer EA. 1990. Pulseto-pulse modulation of transmitter release in the central nervous system. Ann NY Acad Sci 604:211-221.

Chergui K, Suaud-Chagny MF, Gonon F. 1994. Nonlinear relationship between impulse flow, dopamine release and dopamine elimination in the rat brain in vivo. Neuroscience 62:641-645.

Doucet G, Descarries L, Garcia S. 1986. Quantification of the dopamine innervation in adult rat neostriatum. Neuroscience 19:427445.

Dugast C, Suaud-Chagny MF, Gonon F. 1994. Continuous in vivo monitoring of evoked dopamine release in the rat nucleus accumbens by amperometry. Neuroscience 62:647-654.

Dugast C, Brun F, Sotty F, Renaud B, Suaud-Chagny MF. 1997. On the involvement of a tonic D2-autoinhibition in the regulation of pulse-to-pulse evoked dopamine release in the rat striatum in vivo. Naunyn Schmied Arch Pharmacol 355:716-719.

Freeman AS, Meltzer LT, Bunney BS. 1985. Firing properties of substantia nigra dopaminergic neurons in freely moving rats. Life Sci 36:1983-1994.

Gerhardt G, Adams RN. 1982. Determination of diffusion coefficients by flow injection analysis. Anal Chem 54:2618-2620.

Gonon FG. 1988. Nonlinear relationship between impulse flow and dopamine released by rat midbrain dopaminergic neurons as studied by in vivo electrochemistry. Neuroscience 24:19-28.

Gonon F. 1997. Prolonged and extrasynaptic excitatory action of dopamine mediated by $\mathrm{D} 1$ receptors in the rat striatum in vivo. J Neurosci 17:5972-5978.

Grace AA. 1991. Phasic versus tonic dopamine release and the modulation of dopamine system responsivity: a hypothesis for the etiology of schizophrenia. Neuroscience 41:1-24.

Grace AA, Bunney BS. 1983. Intracellular and extracellular electrophysiology of nigral dopamine neurons. I. Identification and characterisation. Neuroscience 10:301-315.

Grace AA, Bunney BS. 1984. The control of firing pattern in nigral dopamine neurons: burst firing. J Neurosci 4:2877-2890.

Higgins MJ, Stone TW. 1995. Bicucculine-resistant paired-pulse inhibition in the rat hippocampal slice. Br J Pharmacol 109:11641168.

Kawagoe KT, Wightman RM. 1994. Characterisation of amperometry for in vivo measurement of dopamine dynamics in the rat brain. Talanta 41:865-874.

Kennedy RT, Jones SR, Wightman RM. 1992. Dynamic observation of dopamine autoreceptor effects in rat striatal slices J. Neurochem 59:609-615.

Langer SZ. 1997. 25 years since the discovery of presynaptic receptors: present knowledge and future perspectives. Trends Pharmacol Sci 18:95-99.

Lee TH, Gee KR, Ellinwood EH, Seidler FJ. 1996. Combining 'cageddopamine' photolysis with fast scan cyclic voltammetry to assess dopamine clearance and release autoinhibition in vitro. J Neurosci 67:221-231.

Limberger N, Trout SJ, Kruk ZL, Starke K. 1991. "Real-time” measurement of endogenous dopamine release during short trains of pulses in slices of rat neostriatum and nucleus accumbens: role of autoinhibition. Naunyn Schmied Arch Pharmacol 344:623-629.
Missale C, Castelletti L, Govoni S, Spano PF, Trabucchi M, Hanbauer I. 1985 . Dopamine uptake is differentially regulated in rat striatum and nucleus accumbens. J Neurochem 45:51-56.

Parsons TD, Coorssen JR, Horstmann H, Lee AK, Tse FW, Almers W. 1995. The last seconds in the life of a secretory vesicle. Cold Spring Harbor Symposia on Quantitative Biology 60:389-396.

Patel J, Kruk ZL. 1996. Both D3 and D2 autoreceptors regulate dopamine release at dopamine axon terminal sites. Br J Pharmacol 119:176P.

Paxinos G, Watson C. 1986. The rat brain in stereotaxic coordinates. Sydney: Academic Press.

Phillips PEM, Stamford JA. 1996. The effect of NMDA and GABA antagonists on striatal dopamine efflux: differential actions in regions with distinct mesostriatal innervation. Proc 7th Int Conf In Vivo Methods, Santa Cruz de Tenerife, 111-112.

Phillips PEM, Stamford JA. 1998. Interaction between dopamine uptake blockade and autoreceptor function in the nucleus accumbens in vitro. Eur J Neurosci 10(Suppl 10):349.

Phillips PEM, Stamford JA. 2000. Differential recruitment of N-, Pand Q-type voltage-operated calcium channels in striatal dopamine release evoked by "regular" and "burst" firing patterns. Brain Res 884:139-146.

Rebec GV, Christensen JR, Guerra C, Bardo MT. 1997. Regional and temporal differences in real-time dopamine efflux in the nucleus accumbens during free-choice novelty. Brain Res 776:61-67.

Rice ME, Nicholson C. 1991. Diffusion characteristics and extracellular volume fraction during normoxia and hypoxia in slices of rat neostriatum. J Neurophysiol 65:264-272.

Robinson DL, Phillips PEM, Budygin EA, Trafton BJ, Garris PA, Wightman RM. 2001. Sub-second changes in accumbal dopamine during sexual behavior in male rats. Neuroreport 12:2459-2452.

Schultz W. 1986. Responses of midbrain dopamine neurons to behavioral trigger stimuli in the monkey. J Neurophysiol 56:1439-1461.

Sokoloff P, Andrieux M, Besancon R, Pilon C, Martres MP, Giros B, Schwartz JC. 1992. Pharmacology of human dopamine D3 receptor expressed in a mammalian cell line: comparison with D2 receptor. Eur J Pharmacol 225:331-337.

Stamford JA, Kruk ZL, Millar J. 1988. Diffusion and uptake of dopamine in rat caudate and nucleus accumbens compared using fast cyclic voltammetry. Brain Res 448:381-385.

Stamford JA, Palij P, Davidson C, Jorm CM, Phillips PEM. 1995. Fast cyclic voltammetry in brain slices. In: Boulton A, Baker GB, Adams RN, editors. Neuromethods 27: Voltammetric methods in brain systems. Totowa, NJ: Humana Press.

White FJ, Wang RY. 1983a. Comparison of the effects of chronic haloperidol treatment on A9 and A10 dopamine neurons in the rat. Life Sci 32:983-993.

White FJ, Wang RY. 1983b. Differential effects of classical and atypical antipsychotic drugs on A9 and A10 dopamine neurons. Science 221:1054-1057.

Williams GV, Millar J. 1990. Concentration-dependent actions of stimulated dopamine release on neuronal activity in rat striatum. Neuroscience 39:1-16.

Wu Y, Pearl SM, Zigmond MJ, Michael AC. 2000. Inhibitory glutamatergic regulation of evoked dopamine release in striatum. Neuroscience 96:65-72. 